\title{
Telomere length assessment in leukocytes presents potential diagnostic value in patients with breast cancer
}

\author{
WOJCIECH BARCZAK $^{1,2}$, NATALIA ROZWADOWSKA ${ }^{3}$, ALEKSANDRA ROMANIUK $^{4}$, NATALIA LIPIŃSKA ${ }^{4}$, \\ NATALIA LISIAK ${ }^{4}$, SYLWIA GRODECKA-GAZDECKA ${ }^{5}$, KRZYSZTOF KSIĄŻEK $^{6}$ and BŁAŻEJ RUBIŚ ${ }^{4}$ \\ ${ }^{1}$ Department of Head and Neck Surgery, Poznan University of Medical Sciences, The Greater Poland Cancer Centre; \\ ${ }^{2}$ Radiobiology Laboratory, Department of Medical Physics, The Greater Poland Cancer Centre, Poznan 61-866; \\ ${ }^{3}$ Institute of Human Genetics, Polish Academy of Sciences, Poznan 60-479; \\ ${ }^{4}$ Department of Clinical Chemistry and Molecular Diagnostics, Poznan University of Medical Sciences, Poznan 60-355; \\ ${ }^{5}$ Department of Oncology, Poznan University of Medical Sciences, Poznan 60-569; ${ }^{6}$ Department of Pathophysiology, \\ Laboratory of Gerontology, Poznan University of Medical Sciences, Poznan 60-781, Poland
}

Received March 5, 2015; Accepted January 5, 2016

DOI: $10.3892 / 01.2016 .4188$

\begin{abstract}
Telomere shortening is associated with cancer development, primarily through the induction of genomic instability. The majority of studies have indicated that individuals with shorter blood telomeres may be at a higher risk of developing various types of cancer. There is increasing evidence that the study of the alterations in telomere length may improve cancer prognosis. The aim of the present study was to verify the use of telomere length parameters in the diagnostics of breast cancer stage. Telomere length was analyzed in the blood leukocytes of 52 patients with breast cancer relative to 47 control subjects using quantitative polymerase chain reaction. The effects of stage, grade, estrogen receptor, progesterone receptor and human epidermal growth factor 2 (HER2) status were assessed. The current study demonstrated that the average telomeric sequence length was significantly shorter in leukocytes from individuals diagnosed with a more severe stage of breast cancer (T2N1M0) than in leukocytes in the early stages of the disease (T1N0M0) $(\mathrm{P}=0.0207)$. Furthermore, the data indicated that telomeres in leukocytes derived from patients with HER $2^{+}$breast cancer were significantly longer compared with those with the HER2 ${ }^{-}$type $(\mathrm{P}=0.0347)$. These results suggest that the assessment of telomeres in blood leukocytes may, at least partially, correspond with breast cancer staging and HER 2 receptor status.
\end{abstract}

Correspondence to: Professor Błażej Rubiś, Department of Clinical Chemistry and Molecular Diagnostics, Poznan University of Medical Sciences, 49 Przybyszewskiego Street, Poznan 60-355, Poland

E-mail: blazejr@ump.edu.pl

Key words: telomere length, telomerase, biomarker, breast cancer, tumor

\section{Introduction}

One of the key characteristics of cancer cells is the upregulated telomerase activity. This enzyme is active in $~ 80-90 \%$ of all cases of cancer $(1,2)$. A lack of telomerase activity in the majority of normal cells (or a significantly lower activity level) is associated with the end replication problem, resulting from the inability of DNA polymerase to complete replication of the terminal end of the chromosome. Thus, chromosomes in normal cells lose 50-100 base pairs at the 5' end during each cell division (3). This mechanism functions as a biological clock, eliminating cells that have lived for too long or long enough to accumulate aberrations or mutations $(4,5)$. The unlimited number of cell divisions may lead to the loss of genetic information; therefore, telomere shortening is a signal for the induction of cell death by apoptosis or p53-dependent aging (6). Consequently, it prevents the transformation of cells. In several types of eukaryotic cells, including cancer cells, telomeres are rebuilt using telomerase $(6,7)$.

Telomerase regulation and its association with carcinogenesis is a complex process. However, it is suspected that changes in the human body, even on a local scale (initiation of neoplasia in a single cell), may be reflected at the molecular level in the whole organism (for example, leukocytes), and vice versa $(8,9)$. Thus, changes in telomerase activity and/or consequent telomere length alterations in peripheral blood cells, including leukocytes and migrating cancer cells, are perceived as potentially promising prediction markers of the carcinogenic process (10). It is understood that cancer cells first go through numerous divisions, resulting in significant telomere shortening and telomerase activity subsequently being restored (11). Consequently, cancer cells typically have short telomeres. It is believed that the shortening of telomeres in cancer cells is also associated with characteristics and prognosis of cancer. Recently, telomere length has been reported to be associated with tumor size, lymph node metastasis, histological grade and specific breast tumor subtypes $(12,13)$. Shorter telomeres in tumor tissue have been associated with more aggressive 
subtypes, including luminal $\mathrm{B}$, human epidermal growth factor 2 (HER2 ${ }^{+}$) and triple-negative tumors (14). Although it is not yet fully understood, these processes may also be reflected in telomere length alteration in peripheral blood leukocytes (15). Therefore, the present study investigated whether telomere length in peripheral blood leukocytes serves as a useful parameter in breast cancer diagnostics.

\section{Materials and methods}

Patients and controls. The study group consisted of 52 women (mean age, $58 \pm 12$ years; BMI, $25.9 \pm 3.53$ ) with histologically diagnosed breast cancer at various stages, based on the World Health Organization criteria. The histopathological classification of breast carcinoma is based on the diversity of the morphological features of the tumor. It includes 20 major tumor types and 18 minor subtypes. A major drawback of this classification is that $70 \%-80 \%$ of the all breast cancer cases will eventually belong to one of the two major histopathological classes, namely invasive ductal carcinomas not otherwise specified or invasive lobular carcinoma (10). All of the patients were recruited from the Department of Oncological Surgery, Poznan University of Medical Sciences (Poznan, Poland). The control group comprised of 47 healthy volunteers and blood donors (all female; mean age, $55 \pm 16$ years; BMI, 25.1 \pm 4.54$)$. The patients and controls were Caucasians from the same region of Poland (Poznan). The study protocol was approved by the Ethics Committee of Poznan University of Medical Sciences (146/11) and written consent was provided by the participating individuals. Tumors were characterized according to histological grade, tumor size, metastasis, lymph node and receptor status [including the estrogen receptor (ER), progesterone receptor (PgR) and HER2] (Table I).

DNA isolation. DNA was extracted from peripheral blood leukocytes as previously described (16), using a Blood Mini DNA Isolation kit (A\&A Biotechnology, Gdynia, Poland) and was stored at $-20^{\circ} \mathrm{C}$. A high concentration sample of genomic DNA was prepared in decimal concentrations that were used to run as a standard curve.

Quantitative polymerase chain reaction ( $q P C R)$. Telomere length was assessed using two pairs of primers, consisting of telomere-specific and single copy gene-specific (albumin) primers $(17,18)$. Primers were selected (Table II) that had previously been demonstrated to work specifically (17), with conditions providing efficiency close to $100 \%\left(2.5 \mathrm{mM} \mathrm{MgCl}_{2}\right.$; $0.5 \mu \mathrm{M}$ primers). Albumin primers were designed using Universal ProbeLibrary (Roche Diagnostics, Indianapolis, IN, USA). Initial denaturation and polymerase activation (hot start) was performed at $95^{\circ} \mathrm{C}$ for $10 \mathrm{~min}$, followed by two cycles of $94^{\circ} \mathrm{C}$ for $15 \mathrm{sec}$ and $49^{\circ} \mathrm{C}$ for $15 \mathrm{sec}$ without fluorescence acquisition. The signal was detected during a further 40 cycles $\left(94^{\circ} \mathrm{C}\right.$ for $10 \mathrm{sec}, 66^{\circ} \mathrm{C}$ for $10 \mathrm{sec}$ and $72^{\circ} \mathrm{C}$ for $10 \mathrm{sec}$ ). Melting analysis (range, $65-95^{\circ} \mathrm{C}$; resolution, $0.2^{\circ} \mathrm{C}$ ) was performed subsequent to qPCR to verify the specificity of the product, and indicated that the melting temperature (Tm) was $81.7^{\circ} \mathrm{C}$. The efficiency of the reaction was no lower than $97.8 \%$. Notably, this result was repeated for all the samples that were analyzed (in serial dilutions). Similarly, the
Table I. Study group characteristics.

\begin{tabular}{|c|c|c|}
\hline \multirow[b]{2}{*}{ Feature } & \multicolumn{2}{|c|}{ Group data } \\
\hline & $\mathrm{n}$ & $\%$ \\
\hline Total patients studied & 52 & 100.0 \\
\hline \multicolumn{3}{|l|}{ Tumor size } \\
\hline $\mathrm{T} 1$ & 31 & 59.6 \\
\hline $\mathrm{T} 2$ & 17 & 32.7 \\
\hline $\mathrm{T} 3$ & 4 & 7.7 \\
\hline \multicolumn{3}{|l|}{ Metastasis } \\
\hline M0 & 43 & 82.7 \\
\hline M1 & 1 & 1.9 \\
\hline Mx & 8 & 15.4 \\
\hline \multicolumn{3}{|l|}{ Lymph nodes } \\
\hline No & 13 & 25.0 \\
\hline N1 & 30 & 57.7 \\
\hline $\mathrm{N} 2$ & 0 & 0.0 \\
\hline N3 & 1 & 1.9 \\
\hline $\mathrm{Nx}$ & 8 & 15.4 \\
\hline \multicolumn{3}{|l|}{ Histological grade } \\
\hline G1 & 13 & 25.0 \\
\hline G2 & 23 & 44.2 \\
\hline G3 & 13 & 25.0 \\
\hline Gx & 3 & 5.8 \\
\hline \multicolumn{3}{|l|}{ ER status } \\
\hline $\mathrm{ER}^{+}$ & 45 & 86.5 \\
\hline $\mathrm{ER}^{-}$ & 7 & 13.5 \\
\hline \multicolumn{3}{|l|}{ PgR status } \\
\hline $\mathrm{PgR}^{+}$ & 39 & 75.0 \\
\hline $\mathrm{PgR}^{-}$ & 13 & 25.0 \\
\hline \multicolumn{3}{|l|}{ HER2 status } \\
\hline $\mathrm{HER}^{+}{ }^{+}$ & 26 & 50.0 \\
\hline HER2- & 26 & 50.0 \\
\hline
\end{tabular}

Tumors were characterized according to histological grade, tumor size, lymph node and receptor status (ER, PgR and HER2). ER, estrogen receptor; PgR, progesterone receptor; HER2, human epidermal growth factor 2 .

reaction conditions for albumin were as follows: Denaturation at $95^{\circ} \mathrm{C}$ for $10 \mathrm{~min}$ (hot start); followed by 45 cycles at $94^{\circ} \mathrm{C}$ for $10 \mathrm{sec}, 61^{\circ} \mathrm{C}$ for $10 \mathrm{sec}$ and $72^{\circ} \mathrm{C}$ for $10 \mathrm{sec}$. The Tm of the products (analysis performed as aforementioned) was $80.7^{\circ} \mathrm{C}$ and the efficiency was $99.6 \%$. The primers and $\mathrm{MgCl}_{2}$ were utilized at $0.5 \mu \mathrm{M}$ and $2.5 \mathrm{mM}$, respectively. Telomere length was assessed using the LightCycler ${ }^{\circledR} 2.0$ Instrument and the LightCycler ${ }^{\circledR}$ FastStart DNA Master SYBR Green I kit (Roche Diagnostics).

Southern blot analysis. Telomere length assessment obtained using qPCR was verified by Southern blot (19), with certain modifications as previously described (20). Briefly, $1.5 \mu \mathrm{g}$ DNA obtained from two samples was digested with the 
Table II. Sequence of primers used in quantitative polymerase chain reaction assays to assess relative telomere length.

\begin{tabular}{ll}
\hline Primer & \multicolumn{1}{c}{ Sequence } \\
\hline Telg & ACACTAAGGTTTGGGTTTGGGTTTGGGTTTGGGTTAGTGT \\
Telc & TGTTAGGTATCCCTATCCCTATCCCTATCCCTATCCCTAACA \\
ALBF & TTTGCAGATGTCAGTGAAAGAGA \\
ALBR & TGGGGAGGCTATAGAAAATAAGG
\end{tabular}

Reference no.

Telg, telomere forward; Telc, telomere reverse; ALBF, albumin forward; ALBR, albumin reverse.

restriction enzymes HinfI and RsaI (Roche Diagnostics); following this, the DNA fragments were separated by gel electrophoresis (Sigma-Aldrich, St. Louis, MO, USA), which was run at $5 \mathrm{~V} / \mathrm{cm}$ in $1 \mathrm{X}$ Tris-acetate-ethylenediaminetetraacetic acid buffer (TeloTAGGG Telomere Length assay kit; Roche Diagnostics), and transferred to a nylon membrane (Roche Diagnostics), according to the manufacturer's protocols. Subsequently, a digoxigenin (DIG)-labeled probe (TeloTAGGG Telomere Length assay kit; Roche Diagnostics) specific to the telomeric sequence was applied and detected using anti-DIG antibody conjugated to horseradish peroxidase (TeloTAGGG Telomere Length assay kit; Roche Diagnostics). Chemiluminesce visualization of telomeric DNA was conducted using the ChemiDoc XRS+ system (BioRad Laboratories, Inc., Hercules, CA, USA) and was analyzed using ImageJ (www.imagej.nih.gov/ij/), which evaluated the mean length of the telomeres for each studied sample (terTRF).

Statistical analysis. Statistical analysis was performed using the Mann-Whitney U test and Student's t-test calculated via Graph Pad Prism 5 (GraphPad Software, Inc., La Jolla, CA, USA). $P<0.05$ was considered to indicate a statistically significant difference.

\section{Results}

Telomere length. The average telomere lengths in the study and control groups were analyzed and no significant statistical difference was observed ( $\mathrm{P}=0.9358$; Fig. 1A). Additionally, the association between the telomere lengths in leukocytes and the tumor stage [according to the tumor node metastasis (TNM) classification] was investigated (10). As presented in Fig. 1B, it was demonstrated that the average length of the telomeric sequences was significantly shorter $(\mathrm{P}=0.0207)$ in leukocytes derived from individuals with breast cancer of a higher stage (T2N1M0) than in leukocytes from patients in the early stages of the disease (T1NOM0). The correlation of ER, PgR and HER status with telomere length was also assessed. As demonstrated in samples derived from HER $2^{+}$patients, telomeres were significantly longer compared with samples from HER2- patients (Fig. 1C; $\mathrm{P}=0.0347$ ). Telomere length was not significantly different between patients that were positive and patients that were negative for $\mathrm{ER}$ or $\mathrm{PgR}(\mathrm{P}=0.1312$ and $\mathrm{P}=0.1145$, respectively; Fig. 1D and E). Also, no association was identified between the histological cancer grade and alterations of telomere length in the peripheral blood cells (G1 vs. $\mathrm{G} 2, \mathrm{P}=0.7381$; $\mathrm{G} 1$ vs. $\mathrm{G} 3, \mathrm{P}=0.3232 ; \mathrm{G} 2$ vs. $\mathrm{G} 3, \mathrm{P}=0.1878$; Fig. 1F).

\section{Discussion}

In terms of telomerase and telomeres as suitable markers to aid cancer therapy and diagnostics, further research is required. Telomerase activity is recognized as a unique feature of cancer cells; however, the specificity of this marker has been questioned, as the activity of this enzyme was previously observed in stem cells, and in certain somatic cells (21-24). Despite this, telomerase activity continues to be recognized as a potential therapeutic target for cancer, primarily due to the likely low number of side effects observed to be associated with such treatment. It is established, however, that the success of any therapy is predominantly reliant on an early and accurate diagnosis. Telomerase activity and telomere length assessment remain to be the most promising factors in early diagnostics. The detection of increased telomerase activity and shortening of telomeres are hypothesized to serve as specific signals of carcinogenesis. According to a number of studies (25-27), the detection of telomerase activity or telomere length alterations may be observed either in migrating cancer cells or in peripheral blood leukocytes. Such results may provide an opportunity to distinguish or qualify patients with differential cancer stages or grades.

In terms of telomere length as a diagnostic factor, certain studies have demonstrated that changes in telomere length are linked to the risk of cancer (28-31). Identification of telomere length is considered to be useful as a prognostic factor, particularly when considering assays based on telomere length analysis in blood cells. Such tests should be efficient and non-invasive.

In the present study, no significant difference in average telomere length between the control subjects and patients with breast cancer was observed. However, significant differences were identified between the telomere length in cells derived from patients with different TNM stages of breast cancer and varying HER statuses. A number of studies observed no association between telomere length and breast cancer risk (32), whilst studies of small telomere length variation (TLV; defined as the coefficient variation of telomere lengths among examined cells) in normal epithelial cells adjacent to the tumor demonstrated that TLV was significantly associated with a 5 -fold (95\% confidence interval $=1.2-22.2$ ) increased risk of breast cancer local recurrence (33). Meta-analyses conducted on bladder, esophageal, gastric, head and neck, ovarian, renal 
A

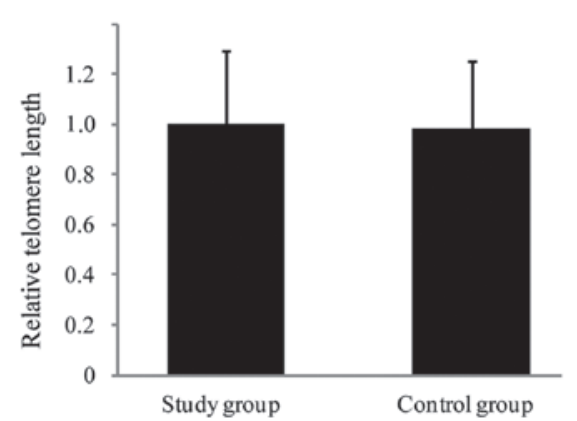

C

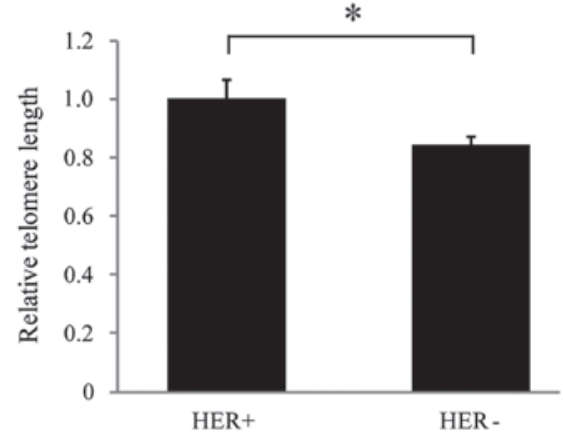

E

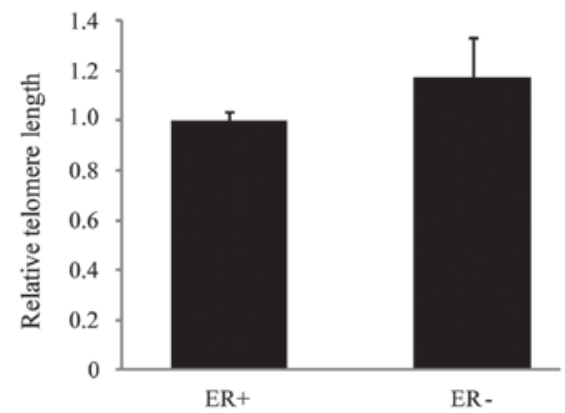

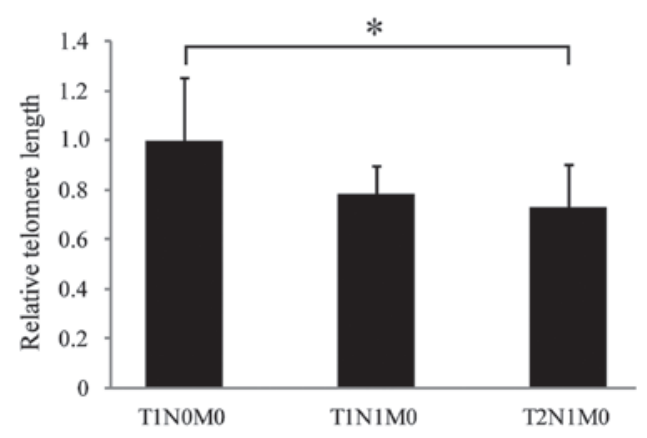

D

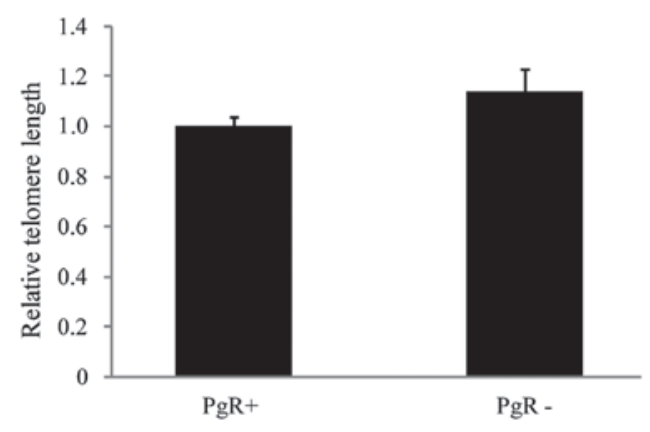

F

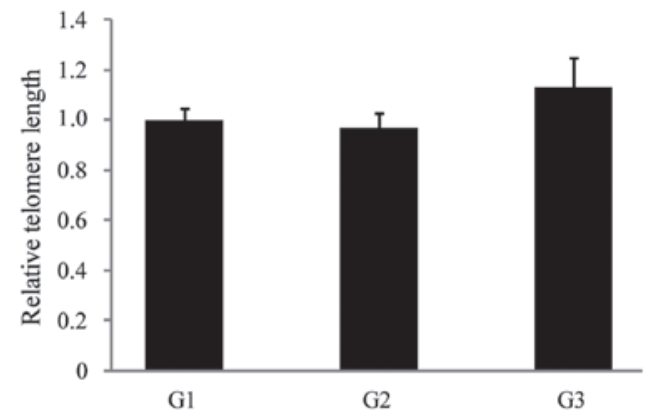

Figure 1. Quantitative analysis of telomere length in peripheral leukocytes from patients with breast cancer (study group) and control subjects, and the correlation with clinical parameters. Relative telomere length was assessed according to protocol previously described by Cawthon (with modifications) (12) using quantitative polymerase chain reaction. Telomere length was presented relative to a single copy gene albumin. Relative length of telomeres, comparing the (A) study and control groups; (B) tumor stage (according to the TNM classification as follows: T1N0M0, small primary tumor and no lymph node involvement or distant metastases; T1N1M0, small primary tumor, sentinel node metastasis with no distant metastases; T2N1M0, larger primary tumor, sentinel node metastasis with no distant metastases); (C) HER status; (D) PgR status; (E) ER status; and (F) tumor grade. *P<0.05, comparison shown by brackets. T, tumor; $\mathrm{N}$, node; M, metastasis; HER2, human epidermal growth factor receptor 2; PgR, progesterone receptor; ER, estrogen receptor; G1/2/3, grades 1/2/3.

and overall cancer identified significant associations between short telomeres and the aforementioned types of cancer (assessed in surrogate and cancer tissues) (34).

The results of the present study are noteworthy, particularly since HER2 overexpression is considered to be an important biological marker of poor prognosis and increased disease aggressiveness, in addition to being a useful indicator of response to anti-HER2 therapy in breast cancer (35). Previous studies have demonstrated that HER2 amplification is associated with increased telomerase reverse transcriptase (hTERT) expression and telomerase activity in cancer cells (36). Similarly, Vageli et al (37) indicated that the mechanism of hTERT transcriptional activation may involve HER2-ER81 interactions; and possible connections between pathways that regulate the expression of HER 2 and hTERT provide an explanation for telomere lengthening as a result of increased telomerase activity. By contrast, Sugishita et al (38) demonstrated that the telomeres in cases of HER2 ${ }^{+}$thyroid cancer are shorter than those of HER2 - cases, and suggested that short telomeres in cancer tissues may serve as a further negative prognostic indicator. However, Shen et al (39) observed increased telomere length among cases of HER $2^{+}$breast cancer, and a significant association between longer telomeres and all-cause mortality among HER2- cases. Such results suggest that simultaneous monitoring of HER2 status and telomere length may provide important information regarding breast cancer development, malignancy and prognosis.

In conclusion, the analysis of telomere length by qPCR may serve as a diagnostic tool reflecting changes in telomere length in leukocytes. This may subsequently result from the genome instability, driving the mechanisms that eventually lead to carcinogenesis. However, it should be noted that, despite the evidence that malignant transformation contributes to telomere length alterations, there are additional factors influencing this parameter, including varying age, gender, xenobiotics/hormones exposition, genetic profile and telomere 
length at birth. As telomere length in breast cancer patients demonstrates a level of prognostic value, future studies should be conducted in larger groups of patients. If this trend is confirmed, measurement of telomere length may enable a quick and noninvasive assessment of potential risk associated with advanced cancer.

\section{Acknowledgements}

The current study was supported by The National Science Centre (grant no. 2011/03/B/NZ7/00512) and the Poznan University of Medical Sciences (grant no. 502-05-03318432-50736).

\section{References}

1. Chen $\mathrm{CH}$ and Chen RJ: Prevalence of telomerase activity in human cancer. J Formos Med Assoc 110: 275-289, 2011.

2. Shtessel L and Ahmed S: Telomere dysfunction in human bone marrow failure syndromes. Nucleus 2: 24-29, 2011.

3. Harley CB, Futcher AB and Greider CW: Telomeres shorten during ageing of human fibroblasts. Nature 345: 458-460, 1990.

4. Oeseburg H, de Boer RA, van Gilst WH and van der Harst P. Telomere biology in healthy aging and disease. Pflugers Arch 459: 259-268, 2010.

5. Watson JM and Riha K: Telomeres, aging, and plants: From weeds to Methuselah - a mini-review. Gerontology 57: 129-136, 2011.

6. Chan SR and Blackburn EH: Telomeres and telomerase. Philos Trans R Soc Lond B Biol Sci 359: 109-121, 2004.

7. de Lange T: How telomeres solve the end-protection problem. Science 326: 948-952, 2009.

8. Barczak W and Rubis B: Telomere length as a prognostic marker in breast and lung cancer. Nowotwory 62: 376-384, 2012

9. Yao YG, Ogasawara Y, Kajigaya S, Molldrem JJ, Falcão RP, Pintão MC, McCoy JP Jr, Rizzatti EG and Young NS: Mitochondrial DNA sequence variation in single cells from leukemia patients. Blood 109: 756-762, 2007.

10. Lakhani SR, Ellis IO, Schnitt SJ, Tan PH and van de Vijver MJ (eds): World Health Organization Classification of Tumours of the Breast. In: World Health Organization Classification of Tumours. Vol. 4. Fourth Edition. IARC Press, Lyon, 2012.

11. Hackett JA and Greider CW: Balancing instability: Dual roles for telomerase and telomere dysfunction in tumorigenesis Oncogene 21: 619-626, 2002.

12. Gramades MM, Telli ML, Balise R and Ford JM: Longer relative telomere length in blood from women with sporadic and familiar breast cancer compared with healthy controls. Cancer Epidemiol Biomarkers Prev 19: 605-613, 2010.

13. Martinez-Delgado B, Yanowsky K, Inglada-Perez L, Domingo S, Urioste M, Osorio A and Benitez $\mathrm{J}$ : Genetic anticipation is associated with telomere shortening in hereditary breast cancer. PLoS Genet 7: e1002182, 2011.

14. Heaphy CM, Subhawong AP, Gross AL, Konishi Y, Kouprina N, Argani P, Visvanathan K and Meeker AK: Shorter telomeres in luminal B, HER-2 and triple-negative breast cancer subtypes. Mod Pathol 24: 194-200, 2011.

15. Shao L, Wood CG, Zhang D, Tannir NM, Matin S, Dinney CP and $\mathrm{Wu} \mathrm{X}$ : Telomere dysfunction in peripheral lymphocytes as a potential predisposition factor for renal cancer. J Urol 178: 1492-1496, 2007.

16. Rubiś B, Hołysz H, Barczak W, Gryczka R, Łaciński M, Jagielski P, Czernikiewicz A, Półrolniczak A, Wojewoda A, Perz K, et al: Study of ABCB1 polymorphism frequency in breast cancer patients from Poland. Pharmacol Rep 64: 1560-1566, 2012.

17. Cawthon RM: Telomere length measurement by a novel monochrome multiplex quantitative PCR method. Nucleic Acids Res 37: e21, 2009.

18. O'Callaghan NJ and Fenech M: A quantitative PCR method for measuring absolute telomere length. Biol Proced Online 13: 3 , 2011.

19. Kimura M, Stone RC, Hunt SC, Skurnick J, Lu X, Cao X, Harley CB and Aviv A: Measurement of telomere length by the Southern blot analysis of terminal restriction fragment lengths. Nat Protoc 5: 1596-1607, 2010.
20. Gruszecka A, Kopczyński P, Cudziło D,Lipińska N, Romaniuk A, Barczak W, Rozwadowska N, Toton E and Rubiś B: Telomere shortening in Down syndrome patients - when does it start? DNA Cell Biol 34: 412-417, 2015.

21. Härle-Bachor $C$ and Boukamp P: Telomerase activity in the regenerative basal layer of the epidermis inhuman skin and in immortal and carcinoma-derived skin keratinocytes. Proc Natl Acad Sci USA 93: 6476-6481, 1996.

22. Hiyama E, Tatsumoto N, Kodama T, Hiyama K, Shay J and Yokoyama T: Telomerase activity in human intestine. Int J Oncol 9: 453-458, 1996.

23. Yasumoto S, Kunimura C, Kikuchi K, Tahara H, Ohji H, Yamamoto H, Ide T and Utakoji T: Telomerase activity in normal human epithelial cells. Oncogene 13: 433-439, 1996.

24. Yui J, Chiu CP and Lansdorp PM: Telomerase activity in candidate stem cells from fetal liver and adult bone marrow. Blood 91: 3255-3262, 1998.

25. Huang YK, Fan XG, Qiu F and Wang ZM: Combined detection of mRNA expression of Alpha-fetoprotein in peripheral blood and telomerase activity of monocytes in hepatocellular carcinoma patients. Hepatogastroenterology 60: 1-5, 2013.

26. Lu L, Zhang C, Zhu G, Irwin M, Risch H, Menato G, Mitidieri M, Katsaros D and $\mathrm{Yu} \mathrm{H}$ : Telomerase expression and telomere length in breast cancer and their associations with adjuvant treatment and disease outcome. Breast Cancer Res 13: R56, 2011.

27. Merchant NB, Dutta SK, Girotra M, Arora M and Meltzer SJ: Evidence for enhanced telomerase activity in Barrett's esophagus with dysplasia and adenocarcinoma. Asian Pac J Cancer Prev 14: 679-683, 2013.

28. Bau DT, Lippman SM, Xu E, Gong Y, Lee JJ, Wu X and Gu J: Short telomere lengths in peripheral blood leukocytes are associated with an increased risk of oral premalignant lesion and oral squamous cell carcinoma. Cancer 119: 4277-4283, 2013

29. Lan Q, Cawthon R, Gao Y, Hu W, Hosgood HD III, Barone-Adesi F, Ji BT, Bassig B, Chow WH, Shu X, et al: Longer telomere length in peripheral white blood cells is associated with risk of lung cancer and the rs2736100 (CLPTM1L-TERT) polymorphism in a prospective cohort study among women in China. PLoS One 8: e59230, 2013.

30. Qin Q, Sun J, Yin J, Liu L, Chen J, Zhang Y, Li T, Shi Y, Wei S and Nie S: Telomere length in peripheral blood leukocytes is associated with risk of colorectal cancer in Chinese population. PLoS One 9: e88135, 2014.

31. Wang S, Chen Y, Qu F, He S, Huang X, Jiang H, Jin T, Wan S and Xing J: Association between leukocyte telomere length and glioma risk: A case-control study. Neuro Oncol 16: 505-512, 2014.

32. Kim S, Sandler DP, Carswell G, De Roo LA, Parks CG, Cawthon R, Weinberg CR and Taylor JA: Telomere length in peripheral blood and breast cancer risk in a prospective case-cohort analysis: Results from the Sister Study. Cancer Causes Control 22: 1061-1066, 2011.

33. Zhou X, Meeker AK, Makambi KH, Kosti O, Kallakury BV, Sidawy MK, Loffredo CA and Zheng YL: Telomere length variation in normal epithelial cells adjacent to tumor: Potential biomarker for breast cancer local recurrence. Carcinogenesis 33: 113-118, 2012.

34. Wentzensen IM, Mirabello L, Pfeiffer RM and Savage SA: The association of telomere length and cancer: A meta-analysis. Cancer Epidemiol Biomarkers Prev 20: 1238-1250, 2011.

35. Martin V, Cappuzzo F, Mazzucchelli L and Frattini M: HER2 in solid tumors: More than 10 years under the microscope; where are we now? Future Oncol 10: 1469-1486, 2014.

36. Papanikolaou V, Iliopoulos D, Dimou I, Dubos S, Tsougos I, Theodorou K, Kitsiou-Tzeli S and Tsezou A: The involvement of HER 2 and p53 status in the regulation of telomerase in irradiated breast cancer cells. Int J Oncol 35: 1141-1149, 2009.

37. Vageli D, Ioannou MG and Koukoulis GK: Transcriptional activation of hTERT in breast carcinomas by the Her2-ER81-related pathway. Oncol Res 17: 413-423, 2009.

38. Sugishita Y, Kammori M, Yamada O, Poon SS, Kobayashi M, Onoda N, Yamazaki K, Fukumori T, Yoshikawa K, Onose H, et al: Amplification of the human epidermal growth factor receptor 2 gene in differentiated thyroid cancer correlates with telomere shortening. Int J Oncol 42: 1589-1596, 2013.

39. Shen J, Terry MB, Liao Y, Gurvich I, Wang Q, Senie RT and Santella RM: Genetic variation in telomere maintenance genes, telomere length and breast cancer risk. PLoS One 7: e44308, 2012. 